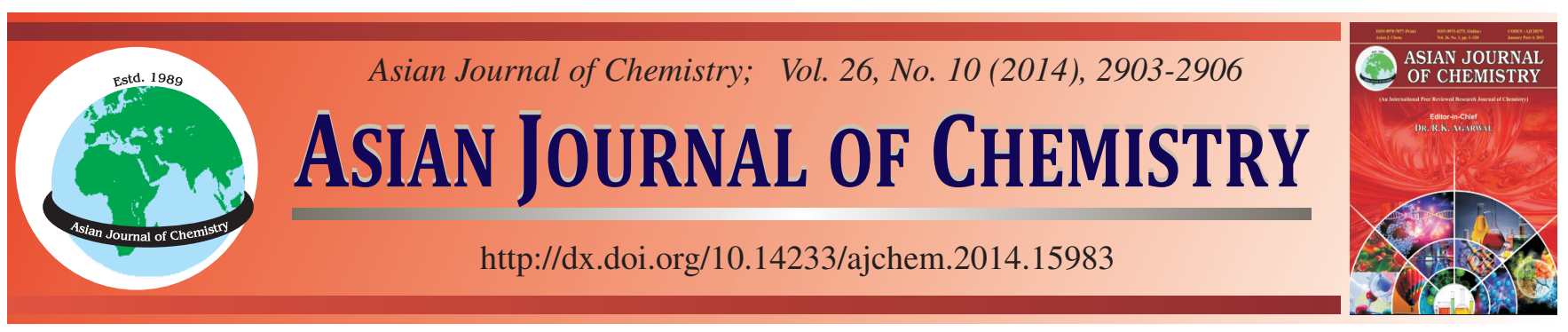

\title{
Preparation of $\mathrm{H}_{3} \mathrm{PW}_{12} \mathrm{O}_{40}$-Titania Composite Materials and Their Photocatalytic Activity Under Visible Light
}

\author{
S.Z. Hu ${ }^{1, *}$, L. MA ${ }^{2}$, S.Y. ZHOU ${ }^{3}$, F.Y. $\operatorname{Li}^{1}$ and Z.P. FAN ${ }^{1}$
}

${ }^{1}$ Institute of Eco-environmental Sciences, Liaoning Shihua University, Fushun 113001, P.R. China

${ }^{2}$ School of Petrochemical Engineering, Liaoning Shihua University, Fushun 113001, P.R. China

${ }^{3}$ School of Environmental and Biological Engineering, Liaoning Shihua University, Fushun 113001, P.R. China

*Corresponding author: Tel: +86 24 23847473; E-mail: hushaozheng001@163.com

Received: 2 July 2013;

Accepted: 21 August 2013;

Published online: 10 May 2014;

AJC-15145

\begin{abstract}
The $\mathrm{H}_{3} \mathrm{PW}_{12} \mathrm{O}_{40}$-titania composite materials were prepared by nonionic-surfactant templating strategy combined with hydrothermal treatment. $\mathrm{X}$-ray diffraction, $\mathrm{N}_{2}$ adsorption, elemental analysis, UV-visible spectroscopy, photoluminescence and X-ray photoelectron spectroscopy were used to characterize the prepared composite materials. The results indicated that the addition of $\mathrm{H}_{3} \mathrm{PW}_{12} \mathrm{O}_{40}$ did not influence the crystallization of $\mathrm{TiO}_{2}$. Hybridization of Ti $3 d$ orbit and W $5 d$ orbit caused the decreased bandgap energies of $\mathrm{H}_{3} \mathrm{PW}_{12} \mathrm{O}_{40}$-titania composite materials, leading to the increased visible light absorption. The obtained catalyst exhibited outstanding photocatalytic activity and stability under visible light.
\end{abstract}

Keywords: $\mathrm{H}_{3} \mathrm{PW}_{12} \mathrm{O}_{40}$, $\mathrm{TiO}_{2}$, Composite material, Photocatalyst, Stability.

\section{INTRODUCTION}

In the area of the advanced oxidation processes, $\mathrm{TiO}_{2}$ has been intensively investigated for the oxidized and even mineralized degradation of various recalcitrant organic pollutants through in situ generated reactive radicals. As a photocatalyst, $\mathrm{TiO}_{2}$ has the advantages of high chemical stability, high photocatalytic activity to oxidize pollutants in air and water and nontoxicity ${ }^{1}$. However, the photocatalytic efficiency of $\mathrm{TiO}_{2}$ is limited due to: (i) the high recombination ratio of photogenerated electrons $\left(\mathrm{e}^{-}\right)$and holes $\left(\mathrm{h}^{+}\right)$on the surface of $\mathrm{TiO}_{2}$ under ultraviolet (UV) light irradiation; and (ii) null photoresponse of $\mathrm{TiO}_{2}$ under visible light irradiation, which severely limits on the development of solar photocatalysis for environmental applications ${ }^{2}$.

It has been reported that $\mathrm{TiO}_{2}$ doped with transition metals can absorb visible light ${ }^{3,4}$. However, the metal cation dopants often serve as recombination centers for the photogenerated electron-hole pairs, leading to a decreased activity. Recently, the substitution of non-metal atoms, such as nitrogen ${ }^{5}$, sulfur ${ }^{6}$, phosphorous $^{7}$, iodine ${ }^{8}$, and boron ${ }^{9}$, for oxygen in the lattice of $\mathrm{TiO}_{2}$ was reported to enhance the catalytic activity of $\mathrm{TiO}_{2}$ under visible light. But the synthesis of nonmetal-doped $\mathrm{TiO}_{2}$ materials is much more difficult, because the lattice exchange requires high temperature and complicated procedures. More recently, much interest has been focused on the surface modifi- cation of $\mathrm{TiO}_{2}$ with organic dyes for the construction of dyesensitized photocatalytic systems under visible light irradia$\operatorname{tion}^{10}$. Since the dye molecules are generally absorbed on rather than chemically bonded to the surface of $\mathrm{TiO}_{2}$, a gradual decrease in activity has been observed.

In the last decades, polyoxometalates (POMs) were widely used as a kind of green catalyst. Many polyoxometalate systems share the same general photochemical characteristics as the semiconductor photocatalysts due to their physical and chemical properties, in terms of molecular and electronic versatility, reactivity and stability ${ }^{11}$. More recently, some polyoxometalates supported on $\mathrm{TiO}_{2}$ composite materials as heterogeneous photocatalysts have been reported successively and exhibit relatively higher photocatalytic degradation abilities towards aqueous organic pollutants ${ }^{12,13,14}$. Li et al ${ }^{12}$ prepared ordered mesoporous $\mathrm{H}_{3} \mathrm{PW}_{12} \mathrm{O}_{40}$-titania materials. The obtained catalysts exhibited excellent photocatalytic activities to degrade methyl orange under solar simulating Xe lamp irradiation. Xie et $a l .{ }^{13}$ prepared $\mathrm{H}_{3} \mathrm{PW}_{12} \mathrm{O}_{40}$ incorporated titania/titanium nanocomposite by post-calcination method. The degradation ability of bisphenol was investigated under UV-A light. Marcì et al. ${ }^{14}$ prepared $\mathrm{H}_{3} \mathrm{PW}_{12} \mathrm{O}_{40}$-titania material by impregnation method and reported its improved photodegradation activity of 2-propanol in gas-solid regime under simulated solar light. However, some limitations still exist in those preparation methods, such as low SBET, aggregation and leaching of the 
Keggin unit at the composite surface and poor control over $\mathrm{H}_{3} \mathrm{PW}_{12} \mathrm{O}_{40}$ loading. All of these lead to reduced photocatalytic activity of prepared catalysts. In this work, a new route nonionicsurfactant templating strategy combined with hydrothermal treatment technique were applied to prepare $\mathrm{H}_{3} \mathrm{PW}_{12} \mathrm{O}_{40}$-titania composite materials with excellent photocatalytic performance and structural stability. The photocatalytic activity was evaluated in the degradation of methylene blue under visible light. The possible mechanism was proposed.

\section{EXPERIMENTAL}

A typical preparatory method of $\mathrm{H}_{3} \mathrm{PW}_{12} \mathrm{O}_{40} / \mathrm{TiO}_{2}$ composite material is described below. P123 (1.5 g) was dissolved in ethanol $(6 \mathrm{~mL})$ at room temperature. $\mathrm{A} \mathrm{TiCl}_{4} / \mathrm{TTIP}$ solution was prepared by dropping $\mathrm{TiCl}_{4}(1.5 \mathrm{~mL})$ and TTIP $(2.5 \mathrm{~mL})$ into ethanol $(6 \mathrm{~mL})$ under vigorous stirring for $10 \mathrm{~min}$. $\mathrm{H}_{3} \mathrm{PW}_{12} \mathrm{O}_{40}(\mathrm{P} / \mathrm{Ti}$ molar ratio of 0.01$)$ was dissolved in water $(10 \mathrm{~mL})$. The above $\mathrm{TiCl}_{4} / \mathrm{TTIP}$ ethanol solution and aqueous $\mathrm{H}_{3} \mathrm{PW}_{12} \mathrm{O}_{40}$ solution was successively added into the P123/ ethanol solution under stirring. The resulting semi-transparent sol was transferred into stainless steel autoclave and subjected to hydrothermal treatment at $160{ }^{\circ} \mathrm{C}$ for $36 \mathrm{~h}$. The resulting white hydrogel was dehydrated at $80{ }^{\circ} \mathrm{C}$ for $24 \mathrm{~h}$ until gel particulate was obtained. The obtained powder was extracted by ethanol at $60{ }^{\circ} \mathrm{C}$ for $3 \mathrm{~h}$ to remove template $\mathrm{P} 123$. The product was denoted as $\mathrm{H}_{3} \mathrm{PW}_{12} \mathrm{O}_{40}(2) / \mathrm{TiO}_{2}$. For comparison, pure $\mathrm{TiO}_{2}, \mathrm{H}_{3} \mathrm{PW}_{12} \mathrm{O}_{40}(1) / \mathrm{TiO}_{2}$ and $\mathrm{H}_{3} \mathrm{PW}_{12} \mathrm{O}_{40}(3) / \mathrm{TiO}_{2}$ were prepared by the same procedure described above but addition $\mathrm{H}_{3} \mathrm{PW}_{12} \mathrm{O}_{40}$ with different $\mathrm{P} / \mathrm{Ti}$ molar ratio $(0,0.005$ and 0.02$)$.

$\mathrm{X}$-ray diffraction patterns of the prepared $\mathrm{TiO}_{2}$ samples were recorded on a Rigaku D/max-2400 instrument using $\mathrm{CuK}_{\alpha}$ radiation $(\lambda=1.54 \AA)$. UV-visible spectroscopy measurement was carried out on a Jasco V-550 spectrophotometer, using $\mathrm{BaSO}_{4}$ as the reference sample. Elemental analysis was performed on a Leeman Plasma Spec (I) ICP-AES. The Brunauer-Emmett-Teller (BET)-specific surface areas $\left(\mathrm{S}_{\mathrm{BET}}\right)$ of the samples were determined through nitrogen adsorption at $77 \mathrm{~K}$ (Micromeritics ASAP 2010). All the samples were degassed at $393 \mathrm{~K}$ before the measurement. X-ray photoelectron spectroscopic measurements were conducted on a Thermo Escalab 250 XPS system with $\mathrm{Al} \mathrm{K}_{\alpha}$ radiation as the exciting source. The binding energies were calibrated by referencing the $\mathrm{C} 1 \mathrm{~s}$ peak $(284.6 \mathrm{eV})$ to reduce the sample charge effect.

Photocatalytic reaction: Methylene blue was selected as model compound to evaluate the photocatalytic performance of the prepared $\mathrm{TiO}_{2}$ particles in an aqueous solution under visible light irradiation. $0.1 \mathrm{~g} \mathrm{TiO}_{2}$ powders were dispersed in $100 \mathrm{~mL}$ aqueous solution of methylene blue (50 ppm) in an ultrasound generator for $10 \mathrm{~min}$. The suspension was transferred into a self-designed glass reactor and stirred for $0.5 \mathrm{~h}$ in darkness to achieve the adsorption equilibrium. In the photoreaction under visible light irradiation, the suspension was exposed to a $110 \mathrm{~W}$ high-pressure sodium lamp with main emission in the range of $400-800 \mathrm{~nm}$ and air was bubbled at $130 \mathrm{~mL} / \mathrm{min}$ through the solution. The UV light portion of sodium lamp was filtered by $0.5 \mathrm{M} \mathrm{NaNO}_{2}$ solution. All runs were conducted at ambient pressure and $30{ }^{\circ} \mathrm{C}$. At given time intervals, $4 \mathrm{~mL}$ suspension was taken and immediately centrifuged to separate the liquid samples from the solid catalyst. The concentrations of methylene blue before and after reaction were measured by means of a UV-visible spectrophotometer at a wavelength of $665 \mathrm{~nm}$. It is the linear relationship between absorbance and concentration of liquid sample in the experimental concentration range. Therefore, the percentage of degradation (D \%) was determined by the absorbances of the liquid sample before and after degradation.

\section{RESULTS AND DISCUSSION}

The XRD patterns of prepared $\mathrm{TiO}_{2}$ catalysts were shown in Fig. 1. Pure anatase $\mathrm{TiO}_{2}$ with characteristic diffractions at $25.2^{\circ}\left(\begin{array}{lll}1 & 0 & 1\end{array}\right), 37.8^{\circ}\left(\begin{array}{lll}0 & 0 & 4\end{array}\right), 48.1^{\circ}(200), 54.7^{\circ}\left(\begin{array}{lll}1 & 0 & 5\end{array}\right)$ and $62.7^{\circ}$ (2 1 1) was shown without $\mathrm{H}_{3} \mathrm{PW}_{12} \mathrm{O}_{40}$ addition (JCPDS No. 21-1272). For the $\mathrm{H}_{3} \mathrm{PW}_{12} \mathrm{O}_{40}$-titania composite materials, pure anatase phase also observed. This indicated that the addition of $\mathrm{H}_{3} \mathrm{PW}_{12} \mathrm{O}_{40}$ did not influence the crystallization of $\mathrm{TiO}_{2}$. Additionally, the diffractions related to the Keggin unit were not found in Fig. 1. This is probably due to the homogeneous dispersion of the Keggin unit throughout the materials. This is consistent with the previous result ${ }^{15}$.

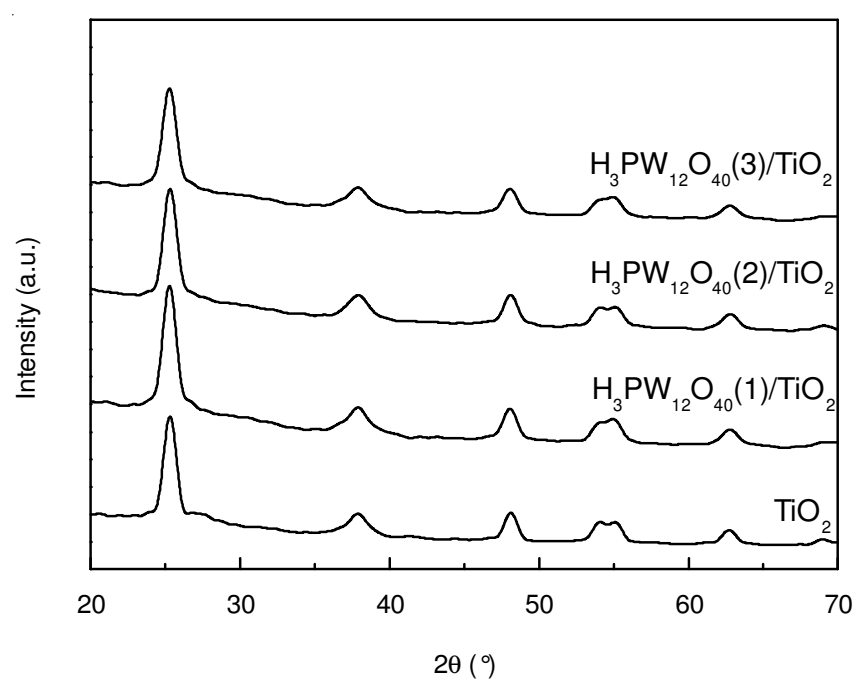

Fig. 1. XRD patterns of prepared $\mathrm{TiO}_{2}$ samples

In Fig. 2, UV-visible spectra of prepared catalysts, no absorption in visible light region for pure $\mathrm{TiO}_{2}$ was observed. However, a tailing absorption in the visible region 400-500 nm were observed for prepared $\mathrm{H}_{3} \mathrm{PW}_{12} \mathrm{O}_{40}$-titania composite catalysts. The absorption bands of the $\mathrm{H}_{3} \mathrm{PW}_{12} \mathrm{O}_{40}$-titania composite catalysts had an obvious red shift compared with pure $\mathrm{TiO}_{2}$. More interestingly, the absorption edges of the $\mathrm{H}_{3} \mathrm{PW}_{12} \mathrm{O}_{40}$-titania composite catalysts continuously extend to the longer wavelength as increase $\mathrm{H}_{3} \mathrm{PW}_{12} \mathrm{O}_{40}$ loading. This result indicated that the band gap of the composite became narrow after the introduction of the Keggin unit into the $\mathrm{TiO}_{2}$ network. In order to confirm this inference, the band gap energy of prepared catalysts were evaluated through Kubelka-Munk formula $^{16}$. The result indicated that the band gap energy of pure $\mathrm{TiO}_{2}$ was $3.1 \mathrm{eV}$, whereas this value decreased to 2.95, 2.95 and $2.9 \mathrm{eV}$ for $\mathrm{H}_{3} \mathrm{PW}_{12} \mathrm{O}_{40}(1) / \mathrm{TiO}_{2}, \mathrm{H}_{3} \mathrm{PW}_{12} \mathrm{O}_{40}(2) / \mathrm{TiO}_{2}$ and $\mathrm{H}_{3} \mathrm{PW}_{12} \mathrm{O}_{40}(3) / \mathrm{TiO}_{2}$, respectively. For pure $\mathrm{TiO}_{2}$, the absorption should be originated from the charge transfer from $\mathrm{O} 2 p$ 
to $\mathrm{Ti} 3 d$ orbit. In the case of the $\mathrm{H}_{3} \mathrm{PW}_{12} \mathrm{O}_{40}$-titania composite catalysts, according to previous report, the absorption band is assigned to the charge transfer from $\mathrm{O} 2 p$ to the new conduction band which is constructed from the hybridization of Ti $3 d$ and W $5 d$ orbit $^{17}$. The energy level of this hybrid orbit is lower than that of Ti $3 d$ orbit, leading to the decreased band gap energy.

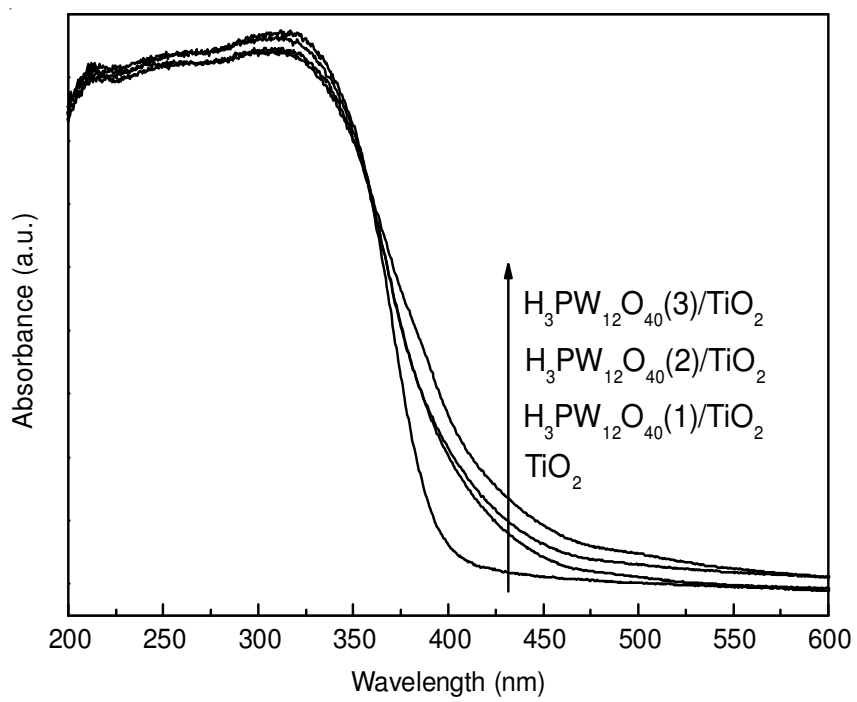

Fig. 2. UV-visible diffuse reflectance spectra of prepared $\mathrm{TiO}_{2}$ samples

Fig. 3 shows the XP spectra of $\mathrm{H}_{3} \mathrm{PW}_{12} \mathrm{O}_{40}(2) / \mathrm{TiO}_{2}$ in the region of $\mathrm{W} 4 f$. Two peaks around 35.9 and $37.9 \mathrm{eV}$ was assigned to $\mathrm{W} 4 f_{7 / 2}$. The binding energy differences, $\Delta \mathrm{E}$, was around $2.0 \mathrm{eV}$. Compared with the XPS results of bulk $\mathrm{H}_{3} \mathrm{PW}_{12} \mathrm{O}_{40}$ reported in previous literature, these values shifted to lower binding energies ${ }^{18}$. This is probably due to the formation of W-O-Ti structure. It is deduced that $\mathrm{W}=\mathrm{O}$ groups within the Keggin units could interact with the surface $\equiv \mathrm{Ti}$ $\mathrm{OH}$ groups within $\mathrm{TiO}_{2}$ via $\mathrm{W}-\mathrm{O}-\mathrm{Ti}$ covalent bonds. Obviously, the electron density of $\mathrm{W}$ in $\mathrm{W}-\mathrm{O}-\mathrm{Ti}$ bond is higher than that in $\mathrm{W}=\mathrm{O}$ group. Therefore, the binding energy in the region of W $4 f$ was decreased. Similar results have also been reported by previous work ${ }^{18}$. The above strong bonding between the two components inhibited the loss of the Keggin unit from $\mathrm{TiO}_{2}$ during the $\mathrm{H}_{3} \mathrm{PW}_{12} \mathrm{O}_{40} / \mathrm{TiO}_{2}$ preparation route.

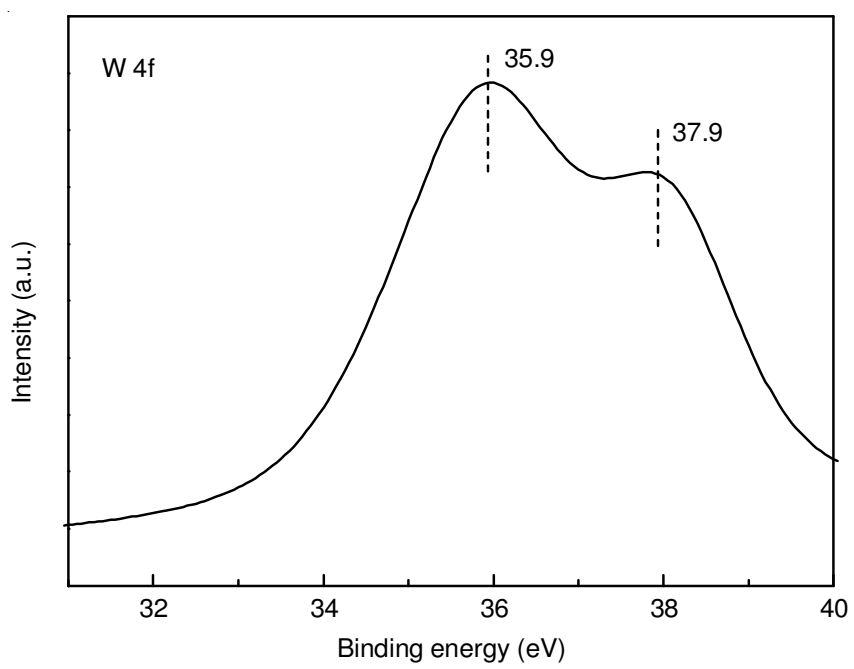

Fig. 3. XP spectra of $\mathrm{H}_{3} \mathrm{PW}_{12} \mathrm{O}_{40}(2) / \mathrm{TiO}_{2}$ in the region of $\mathrm{W} 4 f$
Fig. 4 exhibited the photoluminescence spectra of prepared $\mathrm{TiO}_{2}$ catalysts. The peaks located at 330 were observed for all the catalysts, which is ascribed to the band-band photoluminescence signal ${ }^{19}$. It is shown in Fig. 4 that photoluminescence intensities of $\mathrm{H}_{3} \mathrm{PW}_{12} \mathrm{O}_{40}$-titania composite materials were much lower than that of pure $\mathrm{TiO}_{2}$, indicating the recombination of $\mathrm{h}^{+} / \mathrm{e}^{-}$pairs was reduced after $\mathrm{H}_{3} \mathrm{PW}_{12} \mathrm{O}_{40}$ loading. It is known that $\mathrm{H}_{3} \mathrm{PW}_{12} \mathrm{O}_{40}$ is a very strong Brösted acid and efficient electron trapper by trapping photoexcited electrons into unoccupied W $5 d$ states of the Keggin unit ${ }^{20}$. Therefore, loading $\mathrm{H}_{3} \mathrm{PW}_{12} \mathrm{O}_{40}$ was effective to delay the fast $\mathrm{e}^{-} / \mathrm{h}^{+}$recombination on the surface of $\mathrm{TiO}_{2}$, result in the enhanced quantum efficiency.

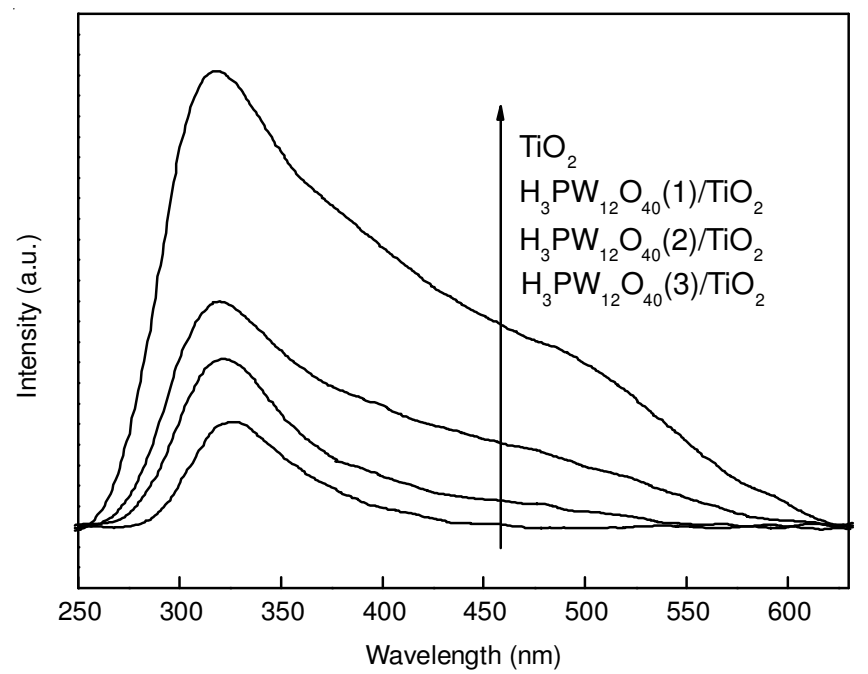

Fig. 4. Photoluminescence spectra of prepared $\mathrm{TiO}_{2}$ catalysts

Fig. 5 shows the photocatalytic performances of prepared $\mathrm{TiO}_{2}$ catalysts under visible light irradiation. Pure $\mathrm{TiO}_{2}$ exhibited poor activity under visible light, whereas the $\mathrm{H}_{3} \mathrm{PW}_{12} \mathrm{O}_{40}$-titania composite catalysts showed much improved photocatalytic performances. These excellent photocatalytic activities are mainly attributed to the following two reasons. One reason should be attributed to the synergistic effect existed between $\mathrm{TiO}_{2}$ and the Keggin unit ${ }^{15}$, which results in the retardation of the recombination of the photoexcited $\mathrm{h}^{+} / \mathrm{e}^{-}$pairs owing to

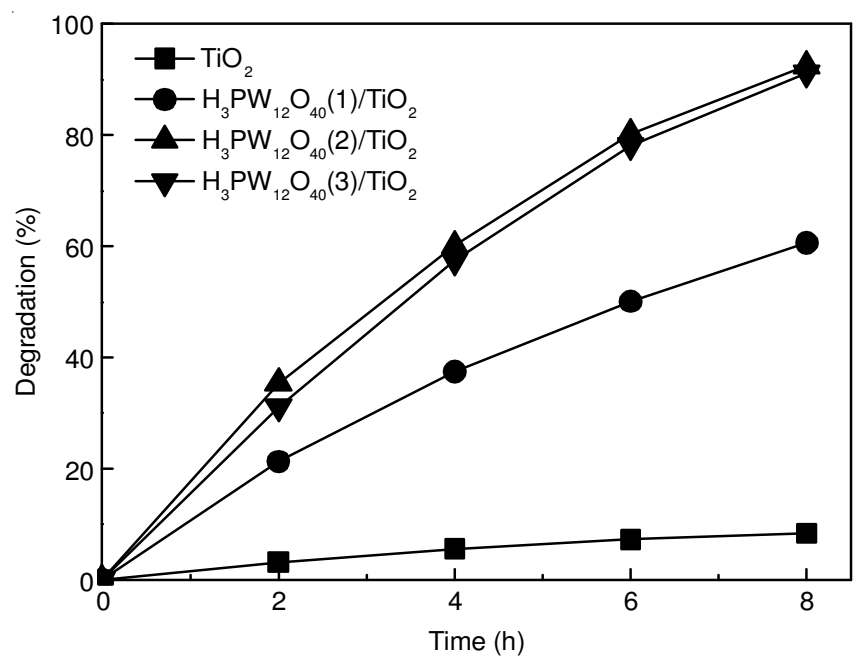

Fig. 5. Photocatalytic performances of prepared $\mathrm{TiO}_{2}$ catalysts under visible light irradiation 
trapping photoexcited electrons into unoccupied W $5 d$ states of the Keggin unit, leading to the enhanced quantum efficiency. The other should be due to the fact that the band gap energies become narrow after the introduction of the Keggin unit into the $\mathrm{TiO}_{2}$ network, which cause the more effective utilization of visible light. Besides, the activity of $\mathrm{H}_{3} \mathrm{PW}_{12} \mathrm{O}_{40}$-titania composite catalysts increased with increase the $\mathrm{H}_{3} \mathrm{PW}_{12} \mathrm{O}_{40}$ content firstly and then decreased when the P/Ti molar ratio beyond 0.1. The nitrogen adsorption results indicated that the SBET of obtained $\mathrm{H}_{3} \mathrm{PW}_{12} \mathrm{O}_{40}$-titania composite catalysts was comparable $\left(202.4,207.3\right.$ and $205.5 \mathrm{~m}^{2} \mathrm{~g}^{-1}$ for $\mathrm{H}_{3} \mathrm{PW}_{12} \mathrm{O}_{40}(1) / \mathrm{TiO}_{2}$, $\mathrm{H}_{3} \mathrm{PW}_{12} \mathrm{O}_{40}(2) / \mathrm{TiO}_{2}$ and $\left.\mathrm{H}_{3} \mathrm{PW}_{12} \mathrm{O}_{40}(3) / \mathrm{TiO}_{2}\right)$. Therefore, it is probably that the excessive loading of $\mathrm{H}_{3} \mathrm{PW}_{12} \mathrm{O}_{40}$ lead to a decreased adsorption sites of $\mathrm{TiO}_{2}$ to methylene blue molecule, which cause the decreased activity of $\mathrm{H}_{3} \mathrm{PW}_{12} \mathrm{O}_{40}(3) / \mathrm{TiO}_{2}$.

To check the catalytic stability of prepared catalyst, the photocatalytic performance of $\mathrm{H}_{3} \mathrm{PW}_{12} \mathrm{O}_{40}(2) / \mathrm{TiO}_{2}$ was investigated in four cycles. After the first catalytic run, the catalyst was removed by centrifugation and filtration and then it was washed by hot water and dried at $100{ }^{\circ} \mathrm{C}$. The recovered catalyst was used for subsequent catalytic runs under the same experimental conditions and regeneration method. No decrease in activity was observed after four cycles (not shown here), indicating that the activity of $\mathrm{H}_{3} \mathrm{PW}_{12} \mathrm{O}_{40}$-titania composite catalyst is stable under visible light irradiation. Besides, the elemental analysis results of fresh and reused $\mathrm{H}_{3} \mathrm{PW}_{12} \mathrm{O}_{40}(2) /$ $\mathrm{TiO}_{2}$ catalysts indicated that the contents of $\mathrm{P}$ and $\mathrm{W}$ were not decreased after four cycles $(0.27 \%$ and $20.2 \%$ for fresh catalyst, $0.26 \%$ and $20.0 \%$ for reused catalyst). The P/W ratio calculated according to those data was 1:12, indicating the original Keggin unit still existed in the composite. Such good structural stability of the $\mathrm{H}_{3} \mathrm{PW}_{12} \mathrm{O}_{40}$-titania composite catalyst is originated from the strong chemical interaction between the Keggin unit and $\mathrm{TiO}_{2}$ matrix.

\section{Conclusion}

The $\mathrm{H}_{3} \mathrm{PW}_{12} \mathrm{O}_{40}$-titania composite materials were prepared by nonionic-surfactant templating strategy combined with hydrothermal treatment. The addition of $\mathrm{H}_{3} \mathrm{PW}_{12} \mathrm{O}_{40}$ did not influence the crystallization of $\mathrm{TiO}_{2}$. Hybridization of $\mathrm{Ti} 3 d$ and $\mathrm{W} 5 d$ orbit caused the decreased band gap energies of $\mathrm{H}_{3} \mathrm{PW}_{12} \mathrm{O}_{40}$-titania composite materials, leading to the increased visible light absorption. Two strong bonding, Ti-O-W structure and acid-base interactions between the Keggin anion and the surface Ti-OH groups, existed simultaneously, which inhibited the drop of the Keggin unit from $\mathrm{TiO}_{2}$ matrix. The improved photocatalytic activities of $\mathrm{H}_{3} \mathrm{PW}_{12} \mathrm{O}_{40}$-titania composite materials were not only due to the synergistic effect between $\mathrm{TiO}_{2}$ and the Keggin unit which retarded the recombination of the photoexcited $\mathrm{h}^{+} / \mathrm{e}^{-}$pairs, but decreased band gap energies which lead to the increased visible light absorption.

\section{ACKNOWLEDGEMENTS}

This work was supported by Program for New Century Excellent Talents in University (No. NCET-11-1011), National Natural Science Foundation of China (No. 41071317, 30972418, 21103077), National Key Technology R \& D Programme of China (No. 2007BAC16B07, 2012ZX07505001), the Natural Science Foundation of Liaoning Province (No. 20092080).

\section{REFERENCES}

1. P.V. Kamat, Chem. Rev., 93, 267 (1993).

2. U.I. Gaya and A.H. Abdullah, J. Photochem. Photobiol. Photochem. Rev., 9, 1 (2008).

3. S. Klosek and D. Raftery, J. Phys. Chem. B, 105, 2815 (2001).

4. H. Yamashita, M. Harada, J. Misaka, M. Takeuchi, K. Ikeue and M. Anpo, J. Photochem. Photobiol. Chem., 148, 257 (2002).

5. S.Z. Hu, F.Y. Li and Z.P. Fan, Bull. Korean Chem. Soc., 33, 199 (2012).

6. H.J. Sun, H.L. Liu, J. Ma, X.Y. Wang, B. Wang and L. Han, J. Hazard. Mater., 156, 552 (2008).

7. Q. Shi, D. Yang, Z.Y. Jiang and J. Li, J. Mol. Catal. B, 43, 44 (2006).

8. R. Abe, K. Sayama, K. Domen and H. Arakawa, Chem. Phys. Lett., 344, 339 (2001).

9. A. Zaleska, J.W. Sobczak, E. Grabowska and J. Hupka, Appl. Catal. B, 78, 92 (2008)

10. D. Chatterjee and A. Mahata, Appl. Catal. B, 33, 119 (2001).

11. Y. Guo, C. Hu, S. Jiang, C. Guo, Y. Yang and E. Wang, Appl. Catal. B, 36, 9 (2002).

12. K. Li, Y. Guo, F. Ma, H. Li, L. Chen and Y. Guo, Catal. Commun., 11, 839 (2010).

13. Y. Xie, L. Zhou and H. Huang, Appl. Catal. B, 76, 15 (2007).

14. G. Marcì, E. García-López, L. Palmisano, D. Carriazo, C. Martín and V. Rives, Appl. Catal. B, 90, 497 (2009).

15. L. Xu, X. Yang, Y.H. Guo, F.Y. Ma, Y.N. Guo, X. Yuan and M.X. Huo, J. Hazard. Mater., 178, 1070 (2010).

16. W. Dong, C.W. Lee, X. Lu, Y. Sun, W. Hua, G. Zhuang, S. Zhang, J. Chen, H. Hou and D. Zhao, Appl. Catal. B, 95, 197 (2010).

17. L. Li, Q. Wu, Y. Guo and C. Hu, Micropor. Mesopor. Mater., 87, 1 (2005).

18. I.V. Kozhevnikov, S. Holmes and M.R.H. Siddiqui, Appl. Catal. A, 214, 47 (2001)

19. J. Liqiang, Q. Yichun, W. Baiqi, L. Shudan, J. Baojiang, Y. Libin, F. Wei, F. Honggang and S. Jiazhong, Sol. Energy Mater. Sol. Cells, 90, 1773 (2006).

20. I.V. Kozhevnikov, Chem. Rev., 98, 171 (1998). 